\title{
Characterization and Evaluation of Thermodynamic Parameters for Egyptian Heap Fired Rice Straw Ash (RSA)
}

\author{
Morsi M. Abou-Sekkina (Corresponding author) \\ Chemistry Department, Faculty of Science, Tanta University \\ Tanta, Egypt \\ Tel: 204-0330-4199Ｅ-mail: univprofdrmorsyabousekkina@yahoo.com \\ Raafat M. Issa \\ Chemistry Department, Faculty of Science, Tanta University, \\ Tanta, Egypt \\ Alam El-Deen M. Bastawisy \\ Mathematics and physics Department, Faculty of Engineering, Tanta University \\ Tanta, Egypt \\ Wael A. El-Helece \\ Chemistry Department, Faculty of Science \\ PO box 2097 Gazan University, KSA \\ Tel: 966-5024-0140Ｅ-mail: wael_elhelece@yahoo.com
}

\begin{abstract}
The composition of the studied ash was confirmed by elemental analysis, IR, XRD spectra, and thermal data (TG \& DTA). These analyses were used to determine thermodynamic parameters such as the activation energy ( $\Delta \mathrm{Ea})$, enthalpy change $\left(\Delta \mathrm{H}^{*}\right)$, entropy change $\left(\Delta \mathrm{S}^{*}\right)$ and free energy change $\left(\Delta \mathrm{G}^{*}\right)$ related to the thermal decomposition process were calculated. Analytical reactions were also used to evaluate the composition of the ash.
\end{abstract}

Keywords: Rice Straw Ash (RSA), Thermal analysis, Thermodynamics of RSA, Chemical characterization of RSA

\section{Introduction}

All agricultural residues are biological forms of renewable energy, rice straw is considered to be the most important of such residues. From this point of view, in most rice producing countries, it is one of the major by-products from rice production process. The husk, consisting mainly of ligno-cellulose and silica, is a poor animal feed source and its main usefulness is its energy content. (James J., 1986; Feng Q., 2004; Smith R.G., 1986; Dass A., 1984; Birch G.G., 1975). The utilization of rice straw as a source of energy production is urgently needed in Egypt while the firing residue is marketable silica. After using any agricultural residue as an energy source (either by direct firing or by gasification) a certain amount of ash consisting mainly of silica and carbon remained. This amount depends mainly on the type of the used agricultural residue and the working conditions such as firing temperature and amount of air used. This also determines the crystalline state of the produced silica and hence its reactivity. (Loehn R.C., 1974; Hobson P.N., 1977; Hicks P.A., 1991; Bewick M.W., 1980). The aim of this work is to study the composition of the ash remained after firing rice straw, this was done using different analytical methods.

\section{Experimental}

Three samples of (RSA) were collected from three different places in delta sample I, sample II, and sample III. Moisture content of (RSA), combustible organic matters and water soluble matters were determined. The composition of the ash was confirmed by elemental analysis, IR and XRD spectra. The thermal studies were carried out using DTA-50, 
TGA-50, Shimadzu Thermogravimetric analyzer (Japan), with a rate of heating $10{ }^{\circ} \mathrm{C} / \mathrm{min}$. Effects of different concentrations of dil. $\mathrm{HCl}$ and $\mathrm{NaOH}$ solutions on ash were also studied.

\section{Results and Discussion}

\subsection{Characterization of RSA by physical methods of analysis.}

\subsubsection{Determination of the moisture content of heap fired RSA}

The moisture content of the RSA samples was determined by heating the samples at $120{ }^{\circ} \mathrm{C}$ till constant weight. The moisture was found to be $3.2 \%$ sample I and $3.6 \%$ for each of samples II and III.

\subsection{Chemical analysis of RSA}

Chemical analysis of the RSA samples was carried out by the recommended methods. Table 1, indicates that silicon dioxide constitutes over $65 \%$ of the total mass of RSA. Other metallic oxides present are $\mathrm{CaO}, \mathrm{Al}_{2} \mathrm{O}_{3}, \mathrm{MgO}$ in addition to traces of iron oxides.

\subsection{Thermogravimetric Analysis (TGA) of RSA}

The TGA curves of the three samples display similar behavior, each curve comprises three main regions. The first region within the range $20-200{ }^{\circ} \mathrm{C}$ corresponds to the removal of the moisture content of the samples $(3.2-3.7 \%)$ together with some volatile materials. These later are higher in sample III than in the other two samples. The second stage within the $200-550^{\circ} \mathrm{C}$ range amounts to $(5.2-11.3 \%)$ would correspond to the burning of the carbonaceous material in the samples. The last step in the range $\left(550-800{ }^{\circ} \mathrm{C}\right)$ is of low mass $(1.4-2.6 \%)$ and may represent the combustion of carbon that was firmly adsorbed on the surface of the solid materials remaining or the volatilization of some metal oxides (Kenawy I.M.M., 1994; Chetterjee P.K., 1968).

\subsection{Differential Thermal Analysis (DTA) of RSA}

Table 3, gives the results of the differential Thermal analysis of the tested heap fired rice straw ash samples.

The DTA curves of the three samples were found to comprise three to five peaks. Comparing these results with those of TGA (table 2), it is evident that the three steps in the TGA curves correspond to steps 1,2 and 3 in the DTA experiment. The other peaks would be due to phase transformations occurring in the solid samples during the rise of temperature (Coats A.W., 1964).

The DTA curves can be used to calculate some thermodynamic parameters of the thermal changes occurring in the tested samples during firing. For this propose the following relations were used (Paunovic M., 2005).

$$
\ln \mathrm{K}=\ln \mathrm{A}-(\mathrm{Ea} / \mathrm{RT})
$$

where:

$\mathrm{K}$ : is the rate constant.

A: the frequency factor.

$\mathrm{R}$ : the gas constant.

Ea: the activation energy.

Plot of $\ln \mathrm{K}$ as a function of $1 / \mathrm{T}$ is a linear relationship; Ea was determined from the slope of this plot.

The following relation can be used to calculate $\Delta \mathrm{H}$ (Paunovic M., 2005).

$$
\ln (\mathrm{K} / \mathrm{T})=\ln (\mathrm{KB} / \mathrm{h})+(\Delta \mathrm{S} / \mathrm{R})-(\Delta \mathrm{H} / \mathrm{RT})
$$

in which:

$\mathrm{KB}$ : is the Boltzman constant.

h: Planks constant.

Plot of $\ln (\mathrm{K} / \mathrm{T})$ vs. 1 / $\mathrm{T}$ gives a linear relationship and $\Delta \mathrm{H}$ can be determined from its slope. Results obtained are summarized in table (3); the abnormal values shown in this table may be ascribed to some side reactions as the combustion of carbon and some phase transformations of silica present in the solid phase (Coats A.W., 1964).

\subsection{IR spectral analysis}

The IR spectra of RSA samples together with samples subjected to some chemical treatments were recorded in the solid state as $\mathrm{KBr}$ discs. The bands of diagnostic importance are collected in table (4), for sake of comparison results for IR spectra of silica samples from the literature are also depicted. The samples involved in the present study are as in scheme (1).The data reveal the existence of the bands characteristic of silica in all samples at $3480-3200 \mathrm{~cm}^{-1}(\mathrm{vO}-\mathrm{H})$, $2430-2330 \mathrm{~cm}^{-1}$ (vSi-H), $1100-1030 \mathrm{~cm}^{-1}\left(\mathrm{SiO}_{2}\right.$ lattice vibration), $800-780 \mathrm{~cm}^{-1}$ (Si-O-Si stretching), and $480-460$ $\mathrm{cm}^{-1}$ (Si-O-Si bending).The vibration modes for the water molecules displayed as brood bands with strong intensity at 
$3445-3425 \mathrm{~cm}^{-1}\left(\gamma \mathrm{H}_{2} \mathrm{O}\right), 1630-1620 \mathrm{~cm}^{-1}\left(\delta \mathrm{H}_{2} \mathrm{O}\right)$ and $980-832 \mathrm{~cm}^{-1}\left(v \mathrm{H}_{2} \mathrm{O}\right)$. The various chemical treatments did not affect much the form of silica present in RSA, which is similar to previous observations (Paunovic M., 2005; Mozzi R., 1970).

The leaching of silica from RSA with $\mathrm{NaOH}$ and then the precipitation of the extracted silica with $\mathrm{HCl}_{\text {or }} \mathrm{H}_{2} \mathrm{SO}_{4}$ yield most probably a mixture of silica and silicic acids which is gathered from the IR spectra. The bands in the region $2900-$ $1750 \mathrm{~cm}^{-1}$ can be ascribed to some organic materials formed during the firing of RS adsorbed on the RSA. These bands disappeared from the samples of silica obtained by leaching with $\mathrm{NaOH}$ and precipitation with acid $(6,7)$ as well as from the residue remaining after leaching. This reflects that such materials were turned soluble during the chemical treatment. The IR bands of unwashed and washed RSA samples (1-5) are quite comparable with those reported for amorphous silica present in natural sources. This reflects that silica present in RSA or samples washed with $\mathrm{NaOH}, \mathrm{HCl}$, or $\mathrm{H}_{2} \mathrm{O}$ is in the amorphous form which is actually the most reactive form of silica.

\subsection{X-Ray Diffraction analysis (XRD)}

The X-ray patterns of the three RSA samples showed no characteristic lines, indicating that the solid contents of the samples are existing mainly in an amorphous form.

\subsection{Chemical characterization of the RSA samples}

\subsubsection{Amount of water soluble matters from the rice straw ash (RSA)}

Results of the tests conducted to detect the amount of water soluble matters in (RSA) are given in table (5). The results indicate that the medium turned alkaline on leaching and the time of stirring has little effect on the amount dissolved. This donates that an equilibrium is readily established between the solid and solution phases. The amount of leached compounds increased obviously on boiling the reaction mixture.

\subsubsection{Effect of dilute hydrochloric acid on RSA}

The effect of treatment with dilute hydrochloric acid (10\%) on the RSA as has been noticed in tables (6a and $b)$ that RSA was affected by loss $14-29 \%$ from its initial weight according to the complete loss of alkali oxides.

\subsubsection{Effect of sodium hydroxide solution on RSA}

The solubility of amorphous $\mathrm{SiO}_{2}$ in sodium hydroxide solution is controlled by many factors, such as sodium hydroxide solution concentration, and temperature; the effect of such factors and the obtained results are summarized in tables (7-9).

\subsubsection{Effect of sodium hydroxide solution concentration}

Tables (7a and b) gives the results for this study, from which the suitable $\mathrm{NaOH}$ solution concentration found is $0.8 \mathrm{M}$. In such a solution about $70.0 \%$ of the total weight of RSA was solublized. This ratio would be about $95.0 \%$ of the total $\mathrm{SiO}_{2}$ found in rice straw ash.

\subsubsection{Effect of treatment duration with sodium hydroxide solution}

To determine the optimum time period for leaching RSA by $0.8 \mathrm{M}$ solution of sodium hydroxide, different time periods $(1,2,4$, and $5 \mathrm{hrs})$ for leaching were conducted as seen in table (8). These tables clears that it is sufficient to boil RSA in $0.8 \mathrm{M} \mathrm{NaOH}$ solution for $2 \mathrm{hrs}$. to dissolve the maximum amount of solid matter from it.

\subsubsection{Effect of temperature}

This test was carried out to determine the suitable temperature for the leaching of RSA by $0.8 \mathrm{M} \mathrm{NaOH}$ solution. Table (9) represents the results obtained. This table shows that more solids are dissolved with temperature rise and the maximum amount dissolved is reached with boiling for two hours.

\section{Conclusion}

Firing of agricultural residues to produce heat energy leads to char production which is the firing residues. This char is a mixture of unburnt carbon, some organic matters, metallic oxides and silicon dioxide. While the amount of silicon dioxide present in the char is dependent upon the type of the agricultural residue, the amount of unburnt carbon is determined by air availability and firing temperature. Silicon dioxide present in the char is either crystalline or amorphous depending mainly upon the firing temperature of the agricultural residue.

Characterization of rice straw ash was done using different methods such as; Chemical composition measurements which showed that RSA constitutes silicon dioxide (over $65 \%$ ) of the total mass of RSA, other metallic oxides present are $\mathrm{CaO}$ (about $2.4 \%), \mathrm{Al}_{2} \mathrm{O}_{3}(1.78 \%), \mathrm{MgO}\left(3.11 \%\right.$ ) in addition to traces of Ferric oxide. Loss on ignition at $1000{ }^{\circ} \mathrm{C}$ was found to be about $9.71 \%$, this includes the moisture, organic matters in addition to the carbon present in the heap fired RSA.

Thermogravimetric analysis (TGA) and differential thermal analysis (DTA) for heap fired rice straw ash were 
undertaken. The obtained results indicated that the ash contains about $3.5 \%$ of its mass as moisture while the amount of organic matters and carbon present was $9.5 \%$, this is compatible with the results of heating heap fired RSA at $120^{\circ} \mathrm{C}$ for $2 \mathrm{hrs}$. followed by burning at $900^{\circ} \mathrm{C}$ till a constant weight.

IR analysis, and XRD measurements have a great importance in detecting the chemical bonding and modes of vibrations between atoms present in the tested samples. These measurements were carried out on different samples from RSA. The obtained results were then compared with reference samples in the literature. This showed that the ash contains amorphous silica as gathered from the band rich IR patterns; which means that the silica present is in its most active state.

Rice Straw Ash samples were also characterized through chemical treatment; with water, hydrochloric acid, and caustic soda. Determination of the amount of water soluble matters in the rice straw ash (RSA) were conducted through leaching of heap fired RSA by either cold water or by boiling water. Leaching with cold water removed about $11.5 \%$ from the ash. During leaching the $\mathrm{pH}$ value of the medium was almost constant at 9.2 which means that the soluble matters are mainly alkali's oxides while leaching of heap fired RSA by boiled water removed about $25 \%$ of its initial mass. This means that the mass of soluble matters was almost duplicated on boiling. This effect was found to be due to that the alkali oxides that dissolved in water affect the dissolution of some $\mathrm{SiO}_{2}$ from RSA. Effect of diluted hydrochloric acid upon RSA was also studied, about $23.0 \%$ of the total mass of the heap fired RSA was leached in cold $10 \% \mathrm{HCl}$ solution while about $70 \%$ of the silica present in RSA was leached by sodium hydroxide. The amount of silica leached increased with increasing the concentration of $\mathrm{NaOH}$ solution, duration of treatment, and the temperature of the treatment media.

\section{References}

Bewick M.W. (1980). Handbook of organic waste conversion. Van Nosteand Reinhold companu, Canada.

Birch G.G. (1975). Food from waste, Applied science publishers. London, pp 319 - 323.

Chetterjee P.K. (1968). Journal of Polymer Science, 6, 3217-3233.

Coats A.W., \& Redfrem J.P. (1964). Kinetic Parameters from Thermogravimetric Data. Nature, 201, 68 - 69.

Dass A. (1984). Pozzolanic behavior of rice husk- ash Building Research and practice 12, 307-311.

Feng Q., Yamamichi H., Shoya M., \& Sugita S. (2004). Study on the pozzolanic properties of rice husk ash by hydrochloric acid pretreatment. Cement and Concrete Research 34, 521-526.

Goyal A., Kunio H., Ogata H., Garg M., Anwar A. M., Ashraf M. \& Mandula. (2007). Synergic effect of wheat straw ash and rice-husk ash on strength properties of mortar. Journal of Applied Science, 7, 3256-3261.

Hicks P.A. (1991). Rice Husk Gasification Technology in Asia, RAPA Publication, 2.

Hobson P.N., \& Robertson A.N. (1977). Waste treatment in Agriculture. Applied science publishers, London, 179 - 185.

James J., \& Rao M.S. (1986). Silica from rice husk through thermal decomposition. Thermocimica Acta 97, 329-336

Kenawy I.M.M., Hafez M.A.H., \& Elsaid Kh.S. (1994). Study of the thermal decomposition of cellulose-hyphan and its complexes with some transition and indium metal ions. Journal of Thermal Analysis and Calorimetry, 42, 1143-1145

Loehn R.C. (1974). Academic press, New York.

Mozzi R., \& Warren B. (1970). The structure of vitreous boron oxide. Journal of Applied Crystallography, 3, 251-257.

Paunovic M., \& Schlesinger M. (2005). Fundamentals of Electrochemical Deposition, (2nd Edition) John Wiley \& Sons, Inc.

Smith R.G., \& Kamwaja G.A. (1986). Measurement of residual stresses in the dissimilar metal weld joint of a safe-end nozzle, CNS Proceedings of the Seventh Annual Conference. Baghdad. October 85-94. 
Table 1. Chemical composition of RSA

\begin{tabular}{|c|c|c|c|c|c|c|c|c|}
\hline Constituants\% & $\mathrm{SiO}_{2}$ & $\mathrm{Al}_{2} \mathrm{O}_{3}$ & $\mathrm{Fe}_{2} \mathrm{O}_{3}$ & $\mathrm{CaO}$ & $\mathrm{MgO} / \mathrm{CaO}$ & $\mathrm{SO}_{3}$ & Loss on ignition & Total \\
\hline Sample I & 65.92 & 1.78 & 0.2 & 2.4 & 3.11 & 0.69 & 9.78 & 83.81 \\
\hline Sample II & 65 & 1.7 & 0.19 & 2.5 & 3.1 & 0.7 & 9.9 & 83.8 \\
\hline Sample III & 66 & 1.9 & 0.18 & 2.4 & 3.2 & 0.8 & 9.8 & 85 \\
\hline
\end{tabular}

Table 2. TGA analysis of RSA samples

\begin{tabular}{|c|c|c|c|c|c|c|}
\hline \multirow[b]{2}{*}{ Sample No. } & \multicolumn{2}{|c|}{ Step(1) } & \multicolumn{2}{|c|}{ Step(2) } & \multicolumn{2}{|c|}{ Step(3) } \\
\hline & $\begin{array}{c}\text { Range } \\
\left({ }^{\circ} \mathrm{C}\right)\end{array}$ & $\begin{array}{c}\text { Wt. Loss } \\
(\%)\end{array}$ & $\begin{array}{c}\text { Range } \\
\left({ }^{\circ} \mathrm{C}\right)\end{array}$ & $\begin{array}{c}\text { Wt. Loss } \\
(\%)\end{array}$ & Range $\left({ }^{\circ} \mathrm{C}\right)$ & $\begin{array}{c}\text { Wt. Loss } \\
(\%)\end{array}$ \\
\hline I & $\begin{array}{c}17.29-201 . \\
02\end{array}$ & 4.86 & \begin{tabular}{|c|}
$202.52-54$ \\
4.79
\end{tabular} & 11.317 & $\begin{array}{c}544.79-799 \\
.69\end{array}$ & 1.425 , \\
\hline II & $\begin{array}{c}19,07-186 . \\
56\end{array}$ & 3.72 & $\begin{array}{c}188.1-475 \\
.16\end{array}$ & 5.236 & \begin{tabular}{|c|}
$478.69-799$ \\
.57
\end{tabular} & 2.512 \\
\hline III & $\begin{array}{c}19.31-158 . \\
88\end{array}$ & 7.34 & \begin{tabular}{|c|}
$159.97-48$ \\
0.5
\end{tabular} & 10.227 & $\begin{array}{c}480.99-799 \\
.4\end{array}$ & 2.643 \\
\hline
\end{tabular}

Table 3. Differential thermal analysis of the tested heap fired rice straw ash

\begin{tabular}{|c|c|c|c|c|c|c|c|c|c|c|c|c|c|}
\hline \multirow{2}{*}{$\begin{array}{c}\text { Sample } \\
\text { Peak }\end{array}$} & \multicolumn{3}{|c|}{ RSA I } & \multicolumn{5}{c|}{ RAS II } & \multicolumn{5}{c|}{ RSA III } \\
\cline { 2 - 13 } & 1 & 2 & 3 & 1 & 2 & 3 & 4 & 5 & 1 & 2 & 3 & 4 & 5 \\
\hline$\Delta \mathrm{H} \mathrm{kj} / \mathrm{m}$ & 11.3 & 15.9 & 5.5 & 5.53 & 68.8 & 14.5 & 10.7 & 6.73 & 37.1 & 7.75 & 67.8 & 11.2 & 22.9 \\
\hline $\begin{array}{c}\Delta \mathrm{Ea} \\
\mathrm{kj} / \mathrm{m}\end{array}$ & 104 & 16.6 & 74.9 & 2.25 & 42.3 & 6.7 & 8.87 & 6.3 & 2.6 & 26.2 & 10 & 15 & 20 \\
\hline$\Delta \mathrm{S} \mathrm{kj} / \mathrm{m}$ & -116.5 & -62.31 & -1103 & -108.6 & 318 & -5208 & -111.1 & -170. & -87.02 & -302 & -102.8 & -139.4 & -632 \\
\hline$\Delta \mathrm{G} \mathrm{kj} / \mathrm{m}$ & 39632 & $\begin{array}{c}23942 \\
9\end{array}$ & 75495 & $\begin{array}{c}48.788 \\
3\end{array}$ & $\begin{array}{c}16395 \\
8\end{array}$ & 32233 & $\begin{array}{c}71705 \\
7\end{array}$ & $\begin{array}{c}1228 \\
26\end{array}$ & 38488 & $\begin{array}{c}15540 \\
5\end{array}$ & $\begin{array}{c}63125 \\
2\end{array}$ & $\begin{array}{c}91500 \\
3\end{array}$ & 45272 \\
\hline
\end{tabular}


Table 4. IR spectra of RSA samples

\begin{tabular}{|c|c|c|c|c|c|c|c|c|c|c|c|}
\hline Sample & \multicolumn{11}{|c|}{ IR spectral bands of diagnostic importance } \\
\hline $\mathrm{L}$ & 440 & 850 & 872 & 905 & 922 & 939 & 1000 & 1035 & 1430 & 1490 & - \\
\hline $\mathrm{C}$ & 440 & 570 & 820 & 860 & 925 & 940 & 950 & - & - & - & - \\
\hline $\mathrm{H}$ & 453 & 706 & 796 & 906 & 935 & 966 & 1020 & 1034 & 1445 & 1610 & 362 \\
\hline $\mathrm{S}$ & 463 & 583 & 667 & 720 & 775 & 832 & 898 & 980 & 1007 & 1040 & 340 \\
\hline 1 & 463 & 791 & 1085 & 1417 & 1631 & - & - & - & - & - & 342 \\
\hline 2 & 463 & 793 & 1088 & 1476 & 1622 & 1728 & 1986 & 2353 & 2851 & - & 342 \\
\hline 3 & 465 & 797 & 1075 & 1484 & 1562 & 1772 & 1866 & 2333 & 2854 & - & 342 \\
\hline 4 & 467 & 798 & 1060 & 1419 & 1631 & 1868 & - & 2337 & - & - & 342 \\
\hline 5 & 480 & 791 & 1055 & 1485 & 1630 & 1864 & 2016 & 2319 & 2855 & - & 344 \\
\hline 6 & 278 & - & 877 & 912 & - & - & 1000 & 1135 & 1424 & 1631 & 363 \\
\hline 7 & 404 & - & 872 & - & - & 951 & - & 1050 & 1476 & 1630 & 362 \\
\hline 8 & 475 & 621 & - & - & 790 & - & - & - & - & 1097 & 342 \\
\hline 9 & 471 & - & - & - & 787 & - & - & - & - & 1098 & 344 \\
\hline \multirow[t]{2}{*}{10} & 462 & - & 668 & - & 790 & - & - & - & 2428 & 1038 & 342 \\
\hline & $\begin{array}{c}\mathrm{Si}-\mathrm{O} \\
-\mathrm{Si}\end{array}$ & $\begin{array}{c}\mathrm{Si}-\mathrm{O}- \\
\mathrm{Si}\end{array}$ & $\begin{array}{c}\mathrm{SiO}_{2} \\
\text { lattice }\end{array}$ & - & $\begin{array}{c}\mathrm{H}_{2} \mathrm{O} \\
\text { bendin }\end{array}$ & - & - & $\begin{array}{l}\text { Si-H } \\
\text { str., }\end{array}$ & - & - & $\begin{array}{c}\mathrm{H}_{2} \\
\mathrm{O}\end{array}$ \\
\hline
\end{tabular}

L- Larnite $\beta \mathrm{Ca}_{2} \mathrm{SiO}_{4}$

C- Calcio olivine $\gamma \mathrm{Ca}_{2} \mathrm{SiO}_{4}$

H- Hillebrandite $\mathrm{Ca}_{2} \mathrm{SiO}_{3}(\mathrm{OH})_{2}$

$\mathrm{S}-\mathrm{Na}_{2} \mathrm{SiO}_{3} .5 \mathrm{H}_{2} \mathrm{O}$ (sodium metasilicate reference sample)

1) Ash sample.

2) Ash washed in $800 \mathrm{ml}$-distilled water by boiling for $2 \mathrm{hrs}$.

3) Ash treated with $10 \% \mathrm{HCl}$ solution by boiling for $2 \mathrm{hrs}$.

4) Ash (control fired at $500{ }^{\circ} \mathrm{C}$ for $4 \mathrm{hrs}$ ) and washed in $800 \mathrm{ml}$ distilled

5) Ash (control fired at $500{ }^{\circ} \mathrm{C}$ for $4 \mathrm{hrs}$ ), treated with $10 \% \mathrm{HCl}$ solution and boiling for $2 \mathrm{hrs}$.

6) $\mathrm{CaO}$ sample prepared by calcination of lime (at $1000^{\circ} \mathrm{C}$ for $1 \mathrm{hr}$ ).

7) $\mathrm{CaO}$ sample prepared by calcination of sugar cane waste.

8) $\mathrm{H}_{2} \mathrm{SiO}_{4}$ prepared from the reaction $\left(\mathrm{Na}_{2} \mathrm{SiO}_{3}+\mathrm{H}_{2} \mathrm{SO}_{4}\right)$.

9) $\mathrm{H}_{2} \mathrm{SiO}_{4}$ prepared from the reaction $\left(\mathrm{Na}_{2} \mathrm{SiO}_{3}+\mathrm{HCl}\right)$.

10) Carbon residue from the reaction between RSA and $0.8 \mathrm{M} \mathrm{NaOH}$, boiling for $4 \mathrm{hrs}$.

Table 5-a. Leaching of RSA with cold water

\begin{tabular}{|c|c|c|c|c|c|c|c|c|c|c|}
\hline \multicolumn{7}{|c|}{ Heap fired ash } & \multicolumn{1}{c|}{ C(500) } & C(700) \\
\hline Time/m & 5 & 10 & 15 & 30 & 45 & 60 & 120 & 180 & 120 & 120 \\
\hline PH & 9.3 & 9.33 & 8.96 & 9.23 & 9.28 & 9.21 & 9.16 & 9.3 & 8.81 & 9.1 \\
\hline Loss\% & 16.5 & 17.0 & 14.4 & 14.8 & 15.4 & 16.4 & 15.0 & 15.0 & 10.0 & 9.0 \\
\hline
\end{tabular}

$\mathrm{C}(500)$ : rice straw ash obtained when burning rice straw at $500{ }^{\circ} \mathrm{C}$.

$\mathrm{C}(700)$ : rice straw ash obtained when burning rice straw at $700{ }^{\circ} \mathrm{C}$. 
Table 5-b. Leaching of RSA with boiled water

\begin{tabular}{|c|c|c|c|c|c|}
\hline Time/m & 40 & 75 & 120 & 120 & 120 \\
\hline PH & 8.44 & 8.46 & 8.07 & 8.40 & 8.30 \\
\hline Loss $\%$ & 30.0 & 26.3 & 27.4 & 30.0 & 24.6 \\
\hline
\end{tabular}

$\mathrm{pH}$ of distilled water used $=7.6$

Table 6-a. Leaching of RSA with $10 \% \mathrm{HCl}$ cold acid solution

\begin{tabular}{|c|c|c|c|c|c|c|c|}
\hline \multicolumn{5}{|c|}{ Heap fired ash } & C(500) & C (700) \\
\hline Time/m & 10 & 30 & 40 & 60 & 120 & 120 & 120 \\
\hline Loss\% & 24.5 & 26.5 & 22.5 & 21.0 & 23.0 & 29.0 & 14.4 \\
\hline
\end{tabular}

$\mathrm{C}(500)$ : rice straw ash obtained when burning rice straw at $500{ }^{\circ} \mathrm{C}$.

$\mathrm{C}(700)$ : rice straw ash obtained when burning rice straw at $700{ }^{\circ} \mathrm{C}$.

Table 6-b. Leaching of RSA with $10 \% \mathrm{HCl}$ acid solution with boiling

\begin{tabular}{|c|c|c|c|c|c|}
\hline \multicolumn{4}{|c|}{ Heap fired ash } & $C(500)$ & $\mathrm{C}(700)$ \\
\hline Time/m & 60 & 120 & 180 & 120 & 120 \\
\hline Loss $\%$ & 14.5 & 23.0 & 25.6 & 29.0 & 19.14 \\
\hline
\end{tabular}

Table 7. Effect of $\mathrm{NaOH}$ solution concentration

\begin{tabular}{|c|c|c|c|c|c|}
\hline \multicolumn{7}{|c|}{ i) Washed ash } \\
\hline NaOH Conc. & $0.08 \mathrm{M}$ & $0.2 \mathrm{M}$ & $0.4 \mathrm{M}$ & $0.8 \mathrm{M}$ & $1.6 \mathrm{M}$ \\
\hline Loss\% & 59.4 & 57.6 & 64.4 & 70.8 & 72.2 \\
\hline \multicolumn{7}{|c|}{ ii) Unwashed ash } & 71.2 & 72.8 \\
\hline Loss\% & 59.6 & 66.6 & 69.4 & 78.9 & \\
\hline \multicolumn{7}{|c|}{ iii) Control fired ash (at $\left.50{ }^{\circ} \mathrm{C}\right)$} \\
\hline Loss\% & 84.06 & 84.48 & 83.4 & 68.97 & \\
\hline
\end{tabular}


Table 8. Effect of treatment duration

\begin{tabular}{|c|c|c|c|c|}
\hline \multicolumn{5}{|c|}{ i) Unwashed RSA in $0.8 \mathrm{M} \mathrm{NaOH}$ at boiling } \\
\hline Time/hrs & 1 & 2 & 4 & 5 \\
\hline Loss $\%$ & 73.2 & 77.6 & 71.2 & 77.4 \\
\hline \multicolumn{5}{|c|}{ ii) Washed RSA } \\
\hline Loss $\%$ & 64 & 70.4 & 70.8 & 67 \\
\hline \multicolumn{5}{|c|}{ iii) Control fired ash (at $500^{\circ} \mathrm{C}$ ) } \\
\hline Loss $\%$ & 83.4 & 83.4 & 83.4 & 83.45 \\
\hline
\end{tabular}

Table 9. Effect of temperature

\begin{tabular}{|c|c|c|c|c|}
\hline \multicolumn{5}{|c|}{ i) Boiling in 0.8M NaOH solution } \\
\hline Time/m & 1 & 2 & 4 & 5 \\
\hline Loss \% & 74 & 77.6 & 71.2 & 77.4 \\
\hline \multicolumn{5}{|c|}{ ii) Heating at $60^{\circ} \mathrm{C}$} \\
\hline Loss \% & 44.6 & 50.4 & 57.6 & \\
\hline \multicolumn{5}{|c|}{ iii) Heating at $40^{\circ} \mathrm{C}$} \\
\hline Loss \% & 28.2 & 30.4 & 36.4 & 37.6 \\
\hline
\end{tabular}

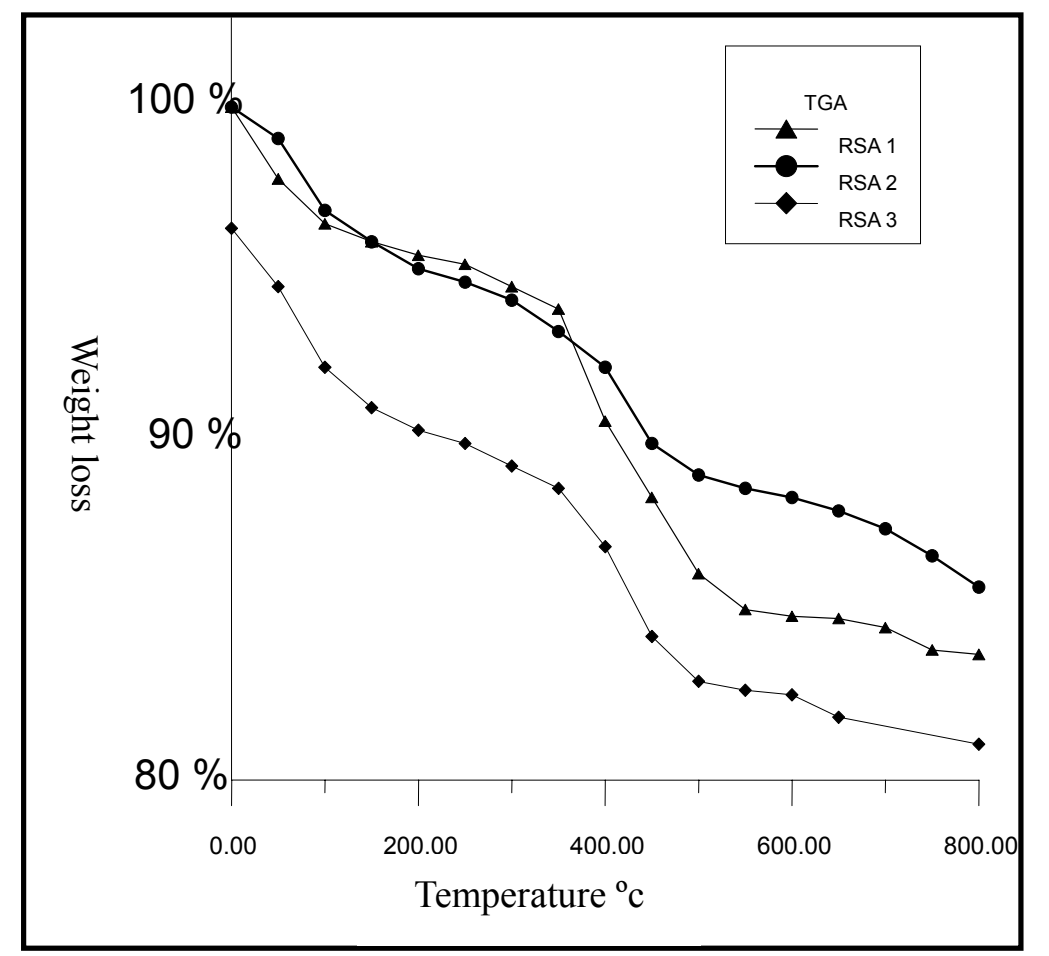

Figure 1. TGA curves for three different RSA samples 